\title{
Chart Rounds in the Digital Age: A Survey of North American Institutions
}

\author{
M. A. Whiton \\ Thomas Jefferson University and Hospitals
}

A. P. Dicker

Thomas Jefferson University and Hospitals

E. J. Wuthrick

Thomas Jefferson University and Hospitals

L. Doyle

Thomas Jefferson University and Hospitals

\section{A. S. Harrison}

Ihomas Jefferson University and Hospitals. follow this and additional works at: hittis://jdc.jefferson.edu/bodinejournal

Part of the Oncology Commons

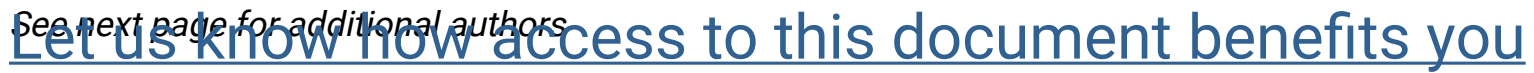

\section{Recommended Citation}

Whiton, M. A.; Dicker, A. P.; Wuthrick, E. J.; Doyle, L.; Harrison, A. S.; and Lawrence, Y. R. (2010) "Chart

Rounds in the Digital Age: A Survey of North American Institutions," Bodine Journal: Vol. 3 : Iss. 1 , Article 43.

DOI: https://doi.org/10.29046/TBJ.003.1.042

Available at: https://jdc.jefferson.edu/bodinejournal/vol3/iss1/43

This Article is brought to you for free and open access by the Jefferson Digital Commons. The Jefferson Digital Commons is a service of Thomas Jefferson University's Center for Teaching and Learning (CTL). The Commons is a showcase for Jefferson books and journals, peer-reviewed scholarly publications, unique historical collections from the University archives, and teaching tools. The Jefferson Digital Commons allows researchers and interested readers anywhere in the world to learn about and keep up to date with Jefferson scholarship. This article has been accepted for inclusion in Bodine Journal by an authorized administrator of the Jefferson Digital Commons. For more information, please contact: JeffersonDigitalCommons@jefferson.edu. 


\section{Chart Rounds in the Digital Age: A Survey of North American Institutions}

\section{Authors}

M. A. Whiton, A. P. Dicker, E. J. Wuthrick, L. Doyle, A. S. Harrison, and Y. R. Lawrence 


\title{
Chart Rounds in the Digital Age: A Survey of North American Institutions
}

\author{
Whiton, M.A., Dicker, A. P., Wuthrick, E.J., Doyle L., Harrison, A.S., Lawrence, Y.R.
}

Department of Radiation Oncology, Thomas Jefferson University and Hospitals, Philadelphia, PA

\section{Purpose/Objective(s)}

In light of public concerns regarding the quality of radiation treatment delivery, we surveyed the utilization of "chart rounds" or peer-review quality assurance meetings, within North American academic institutions.

\section{Material/Methods}

An anonymous web-based survey of chief residents (US) and residency program directors (Canada) was performed. Questions were designed to assess patient volume, treatment complexity and general chart round practices.

\section{Results}

Fifty-nine of 91 (65\%) responded (US, n=57; Canada, $n=2)$. Over $80 \%$ of institutions review all external beam treatments. Rates were much lower for other modalities (radiosurgery 60\%; brachytherapy 50\%). Notably, $42 \%$ of institutions never review prostate brachytherapy cases, while $31 \%$ never review gynecologic brachytherapy cases. Patient history, chart documentation and dose prescription were reviewed in $>79 \%$ institutions, while the finer details of dosimetry (beams, wedges), isodose coverage, IMRT constraints, dose-volume histograms were reviewed only in $62 \%, 59 \%, 40 \%$ and $50 \%$ of cases respectively. Conebeam images were never reviewed in $51 \%$ of institutions. The median number of patients on treatment at any one time was between 100-125. Fifty-eight percent (58\%) of responding institutions hold chart-rounds for less than 2 hours per week. The median amount of time spent per patient was 3.4 minutes (range 0.712). To provide a context in which quality assurance practices could be analyzed, we ascertained the range of highly complex treatments available at each institution, such as SBRT or pelvic IMRT. The median number of highly complex-techniques available was 8 (out of a max 9). No correlation was found between the complexity of techniques used and the time spent per patient for QA purposes. Chart-rounds led to both minor and major treatment changes. Sixty-five percent (65\%) of institutions report that minor alterations (defined as a small MLC change/re-port-film) after chart-rounds were made to less than $10 \%$ of treatment plans, while $32 \%$ report minor changes to $10-30 \%$ of treatment plans. Seventy-five percent (75\%) of institutions report that less than $10 \%$ of treatment plans require a major alteration (change to dose prescription or re-plan with dosimetry), while $11 \%$ report major changes to 10 - 30\% of treatment plans. Fourteen percent (14\%) of institutions never make major treatment plan alterations, while $2 \%$ never make minor alterations.

\section{Conclusion}

The practice of QA chart-rounds appears inconsistent among North American academic institutions. Despite the fact that chart rounds seldom review the full range of critical data available since the advent of 3D planning, changes are nonetheless frequently made. Brachytherapy and radiosurgical procedures are rarely reviewed. The potential effect of a more thorough QA review on patient outcomes is not known, but may be an increasing area of government and medical-legal scrutiny. 